\title{
Can emergency physicians accurately rule out clinically important cervical spine injuries by using computed tomography?
}

\author{
Hendrik P. Van Zyl, MBChB, CCFP(EM)*; James Bilbey, $\mathrm{MD}^{\dagger}$; Alan Vukusic, MD, CCFP(EM)*; \\ Todd Ring, MD, CCFP(EM)*; Jennifer Oakes, MD, FACEP*; Lykke D. Williamson, MD, CCFP(EM)*; \\ Ian V. Mitchell, MD*
}

\section{ABSTRACT}

Objective: Emergency physicians are expected to rule out clinically important cervical spine injuries using clinical skills and imaging. Our objective was to determine whether emergency physicians could accurately rule out clinically important cervical spine injuries using computed tomographic (CT) imaging of the cervical spine.

Method: Fifteen emergency physicians were enrolled to interpret a sample of 50 cervical spine CT scans in a nonclinical setting. The sample contained a $30 \%$ incidence of cervical spine injury. After a 2-hour review session, the participants interpreted the CT scans and categorized them into either a suspected cervical spine injury or no cervical spine injury. Participants were asked to specify the location and type of injury. The gold standard interpretation was the combined opinion of two staff radiologists.

Results: Emergency physicians correctly identified 182 of the 210 abnormal cases with cervical spine injury. The sensitivity of emergency physicians was $87 \%$ (95\% confidence interval [Cl] 82-91), and the specificity was $76 \%(95 \% \mathrm{Cl} 74-77)$. The negative likelihood ratio was $0.18(95 \% \mathrm{Cl} 0.12-0.25)$.

Conclusion: Experienced emergency physicians successfully identified a large proportion of cervical spine injuries on CT; however, they were not sufficiently sensitive to accurately exclude clinically important injuries. Emergency physicians should rely on a radiologist review of cervical spine CT scans prior to discontinuing cervical spine precautions.

\section{RÉSUMÉ}

Objectif: Les urgentologues devraient être en mesure d'écarter l'existence de lésions, importantes sur le plan clinique, de la colonne cervicale en s'appuyant sur leurs compétences cliniques et l'imagerie. L'étude visait à déterminer si les urgentologues pouvaient écarter correctement l'existence de lésions, importantes sur le plan clinique, de la colonne cervicale sur le plan clinique à l'aide de l'imagerie par tomodensitométrie de la colonne cervicale.

Méthode: Quinze urgentologues ont accepté d'interpréter un échantillon de 50 tomodensitogrammes (TDM) de la colonne cervicale en milieu non clinique; I'échantillon comptait $30 \%$ de cas de lésion de la colonne cervicale. Après une séance de formation de 2 heures, les participants ont interprété les TDM et les ont classés en deux catégories: lésion possible et absence de lésion. Les participants devaient préciser le siège des lésions et leur type. L'interprétation de référence reposait sur l'avis de deux radiologistes, membres du personnel.

Résultats: Les urgentologues ont bien identifié 182 cas de lésion de la colonne cervicale sur 210. La sensibilité des urgentologues était de $87 \%$ (intervalle de confiance [IC] à $95 \%$ 82-91) et la spécificité de $76 \%$ (IC à 95\% 74-77). Le quotient de vraisemblance négatif s'est établi à 0.18 (IC à 95\% 0.12-0.25).

Conclusions: Les urgentologues expérimentés ont réussi à identifier, dans une grande proportion, les lésions de la colonne cervicale sur les TDM; toutefois, la sensibilité n'était pas suffisamment élevée pour écarter correctement l'existence de lésions importantes sur le plan clinique. Les urgentologues devraient demander à des radiologistes d'examiner les TDM de la colonne cervicale avant de lever les mesures de précaution relatives à ce type de blessure.

Keywords: cervical spine injury, computed tomography, emergency physician, sensitivity, trauma

In emergency departments (EDs) and particularly in trauma referral centres, it is expected that emergency physicians expediently and safely rule out acute cervical spine injuries that occur in 2 to $6 \%$ of blunt trauma

From the *Emergency Department, Royal Inland Hospital, Kamloops, BC; †Diagnostic Imaging Department, the Royal Inland Hospital, Kamloops, BC.

Correspondence to: Dr. Henk van Zyl, Emergency Department, Royal Inland Hospital, 311 Columbia Street, Kamloops, BC V2C 2T1; hpvanzyl@ hotmail.com.

This article has been peer reviewed. 
presentations. ${ }^{1,2}$ Currently, emergency physicians assess the cervical spine of low-risk trauma patients by employing clinical judgment and using clinical decision rules (CDRs), such as the Canadian Cervical Spine Rule (CCSR) ${ }^{3}$ and the NEXUS rule. ${ }^{4}$ These CDRs are used to determine the need for $x$-ray imaging of the cervical spine. The use of computed tomography (CT) for ruling out cervical spine injury is replacing plain radiography as the preferred imaging modality for moderate- to high-risk trauma patients. ${ }^{5}$ CT has a higher sensitivity for traumatic injury than plain radiography. A 2005 meta-analysis found $99 \%$ sensitivity for CT versus $52 \%$ for plain radiography. ${ }^{6}$ CT demonstrates bony structures in finer detail than plain radiography. In 2008, the eighth edition of Advanced Trauma Life Support recommended CT as the primary imaging modality to assess cervical spine injury in major trauma. ${ }^{7}$ The 2009 published guidelines from the Eastern Association for the Surgery of Trauma Practice Management Guidelines Committee strongly support the use of CT to supplant plain radiography for cervical spine imaging after major trauma. ${ }^{8}$

One important downside of CT imaging of the cervical spine is the need for expert radiologist interpretation, which can prolong patient time in cervical spine precautions. Many EDs do not have 24-hour radiology reporting coverage. After-hours radiologic coverage may be provided through pager, teleradiology, or nighthawk services. ${ }^{9}$ Sites with no after-hours service must either transfer patients for CT imaging or hold patients in the ED overnight for CT imaging in the morning. This variance in radiologic coverage and high radiologic workloads can result in delays in obtaining a formal radiology opinion. Delay in clearing cervical spine precautions has certain risks, including an increased morbidity and risk of decubitus ulceration, increased intensive care unit care, increased ED overcrowding, and delay of surgical procedures. ${ }^{10}$ Current best practice aims to have the initial hard collar removed or replaced with a specialty collar as soon as possible. ${ }^{8}$

Emergency physicians can accurately rule out clinically important intracranial pathology using CT. Harding and colleagues showed missed pathology rates of 1 in 48 cases $(2 \%)$ for subarachnoid hemorrhage (with no harm to the 1 missed patient), and emergency physicians missed 9 abnormalities in 442 trauma cases (2\%) (with harm to only 1 patient of the 9 missed cases). ${ }^{11}$ It is the current practice in many EDs, including our own, for emergency physicians to interpret unenhanced head CT scans themselves.

We contemplated whether the practice of emergency physicians interpreting unenhanced head CT scans could be safely applied to the interpretation of cervical spine CT scans. In some EDs, emergency physicians are already practicing in this manner for selected cases. There is currently no literature examining emergency physicians' ability in this regard. The objective of this study was to determine the sensitivity of emergency physician interpretation of cervical spine CT scans.

\section{METHODS}

Fifteen emergency physicians from a single level II trauma centre with approximately 54,000 emergency visits per year volunteered for this prospective observational study. The range of postgraduate experience was between 2 and 21 years (average 13.3 years). The qualifications of participants were as follows: 12 CCFP(EM), 1 FRCPC, 1 FACEP, and 1 LMCC with 21 years of emergency experience. None of the participants had previous formal radiology training. All participants attended a 2-hour review lecture consisting of a review of cervical spine anatomy and fractures identifiable on CT. The participants were also given a brief individual orientation of the CT imaging system (PACS), enabling them to use the different views and reconstructions of the CT of the cervical spine during the study.

Participants interpreted the same sample of 50 trauma-related cervical spine CT scans. The sample set was selected by one of the investigators, a staff radiologist at our hospital, from the database of trauma cases that presented to our hospital. The sample set of cervical CT scans included a wide variety of injury types.

Participants were asked to categorize each CT scan as either a suspected cervical spine injury or no cervical spine injury. They were asked to report the location and type of injury when they suspected a cervical spine injury. All questionnaires were submitted anonymously and coded by numbers only.

The gold standard for interpretation was the opinion of two staff radiologists. The first review was by the original radiologist reporting on the case. The investigating radiologist then reviewed each of these 
cases again, when selecting them for the study, in an unblinded fashion. All cervical spine injuries were considered clinically important unless they had one of the injuries listed in Table 1.

We decided a priori that a sensitivity of at least $95 \%$ would be required to recommend adoption of emergency physician CT cervical spine interpretation. We calculated that we would require a sample that included 200 positive cases to achieve a sufficiently narrow $95 \%$ confidence interval (CI) $( \pm 3 \%)$ around an anticipated sensitivity of $98 \%$, such that the lower bound of the CI would exceed our desired 95\% sensitivity threshold.

The sample set contained an artificially elevated incidence of injury of $30 \%$. This enabled the study to have sufficient power within the constraints of having a limited number of emergency physicians participating while keeping their time commitment reasonable. Although participants were made aware of an elevated incidence of injury in the sample group, they were blinded to the true percentage of cases with cervical spine injury.

The Interior Health Research Ethics Board approved the study, and consent for participation was obtained from all physicians.

The primary analysis was the sensitivity of emergency physicians in identifying the cases with clinically important cervical spine injuries. Secondary analyses included the specificity, negative predictive value, positive predictive value, and likelihood ratios and successful identification of the exact location and type of fracture. Statistical analysis was performed by an independent statistician using SPSS software (IBM, Armonk, NY).

\section{RESULTS}

Each emergency physician reviewed 50 cases, and 49 were included in the final analysis. Of the 735 cases in the final analysis, 210 had important cervical spine injuries. The participants correctly identified 182

Table 1. Cervical spine injury not clinically important

Isolated avulsion fracture of osteophyte

Isolated fracture of a transverse process not involving a facet joint Isolated fracture of a spinous process not involving the lamina Simple compression fracture involving $<25 \%$ of the vertebral body height cervical spine injuries and missed 28 cervical spine injuries (Table 2).

The sensitivity of the emergency physicians in identifying clinically important cervical spine injuries on CT scan was $87 \%$ (95\% CI 80.2-93.2). The specificity was $76 \%$ (95\% CI 74-77). The positive predictive value was $59 \%$ (95\% CI 56-62). The negative predictive value was $93 \%$ (95\% CI 91-95). The positive likelihood ratio was 3.6 (95\% CI 3.1-4.0). The negative likelihood ratio was 0.18 (95\% CI $0.12-$ $0.25)$.

The 28 missed cervical spine injuries all stem from 6 of the pathologic sample cases (Table 3). Specifically, 18 of the 28 missed cervical spine injuries came from 2 specific cases within the sample set, namely a case with an occipital condyle fracture (Figure 1) and another with a $\mathrm{C} 4$ extension teardrop fracture (Figure 2).

One case was excluded from analysis. The case had two significant fractures: an atlanto-occipital dislocation (AOD) and a C7 fracture. All participants correctly identified the case as a suspected cervical spine injury (sensitivity of 100\%); however, when describing the fractures, 10 of the participants mentioned only the C7 fracture and not the AOD. It was unclear whether the participants were unable to identify the AOD or whether they did not mention it because they already identified the case as being suspicious for another fracture.

\section{DISCUSSION}

This study examined the ability of emergency physicians to detect clinically important cervical spine injury using CT. Although the results indicate that experienced emergency physicians could identify a large proportion of the clinically important cervical spine injuries using CT, they were unable to accurately rule out all cervical spine injuries.

Determining an acceptable sensitivity level was difficult. A recent study showed that on initial interpretation of single-pass pan-scanning in major trauma, radiologists achieved a sensitivity of only $84.6 \%$ for head and neck injuries. ${ }^{12}$ By consensus of regional emergency physicians, an anticipated sensitivity of $98 \%$ with a narrow $95 \%$ CI (such that the lower bound of the CI would exceed a desired 95\% sensitivity threshold) was used for the purpose of sample size calculation. The ideal sensitivity as achieved in the $\operatorname{CCSR}^{3}$ would always be $100 \%$. The 


\begin{tabular}{|c|c|c|c|}
\hline \multirow[b]{2}{*}{ Participant } & \multicolumn{2}{|c|}{ Radiologist } & \multirow[b]{2}{*}{ Total } \\
\hline & Clinically important C-spine injury & No clinically important C-spine injury & \\
\hline Suspected C-spine injury & 182 & 127 & 309 \\
\hline No C-spine injury & 28 & 398 & 426 \\
\hline Total & 210 & 525 & 735 \\
\hline
\end{tabular}

$87 \%$ sensitivity achieved in this study was clearly inadequate, and emergency physicians should continue to rely on radiologist review of cervical spine CT scans.

The study has some limitations. The participants had only a 2-hour prestudy cervical spine CT review session, and this could be argued to be inadequate. The physician group, however, had already received emergency medicine training and had experience with CT scans from clinical practice. Another limitation was that the emergency physicians were blinded to the clinical presentation of the patient. Clinical assessment of the patient is a large part of the emergency physician decision-making process. It is possible that the sensitivity could have been higher if the emergency physicians had been given the opportunity to examine the patient prior to interpreting the cervical CT scan. Another issue was patient selection in the sample group. At our institution, emergency physicians would

\begin{tabular}{|l|l|}
\hline Table 3. Clinically important cervical spine injury \\
\hline Type of fracture & $\begin{array}{c}\text { Number of times } \\
\text { missed (\% of } \\
\text { ERPs) }\end{array}$ \\
\hline 1. Occipital condyle fracture & $9(60)$ \\
2. C4 vertebral body small extension teardrop & $9(60)$ \\
3. C6/7 transverse process + posterior & $4(27)$ \\
element fracture & $3(20)$ \\
4. C6 lateral mass fracture & $2(13)$ \\
5. C7 facet fracture & $1(7)$ \\
6. C5 lamina + C6 facet fracture & 0 \\
7. C3 bilateral facet fracture, postavulsion & 0 \\
8. C2 posterior arch fracture & 0 \\
9. C2 odontoid fracture & 0 \\
10. C6 burst fracture, C5 post-chip avulsion & 0 \\
11. C1 ring fracture, C2 odontoid fracture & 0 \\
12. C6-C7 bilateral facet lock and lateral mass & \\
fracture & 0 \\
13. C5 unilateral facet lock, C5-C6 facet & \\
fracture & 0 \\
14. C2 Jefferson fracture & \\
\hline ERP = emergency room physician. &
\end{tabular}

not clear cervical spine precautions on obtunded multiple-trauma patients; however, these patients were included in the sample set of CT scans. It could be argued that these types of cases should have been excluded. We believed that if emergency physicians were unable to identify significant pathology on CT scan (in high-acuity cases), then they might be even less likely to identify cervical spine injuries in lower-acuity cases, where cervical spine injuries could be more subtle.

The study highlights the need for additional training for emergency physicians in the interpretation of cervical spine CT scans. Currently available ED

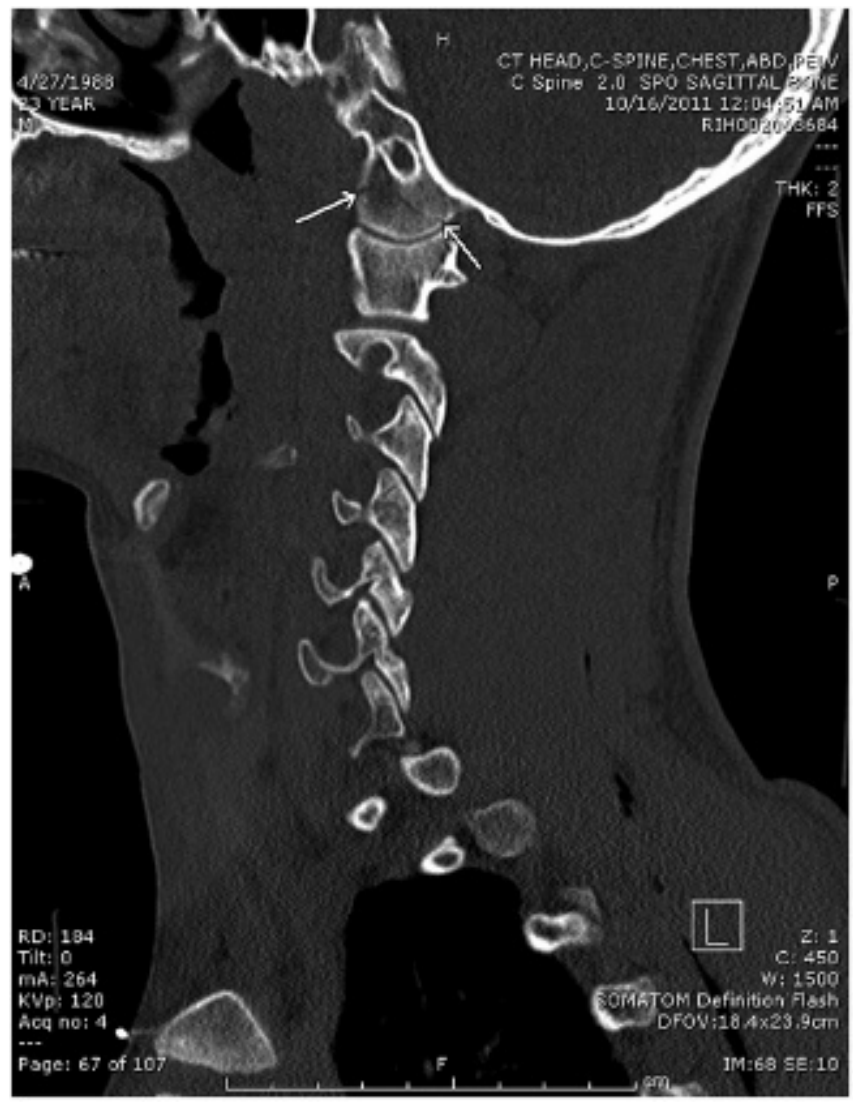

Figure 1. Occipital condyle fracture. 


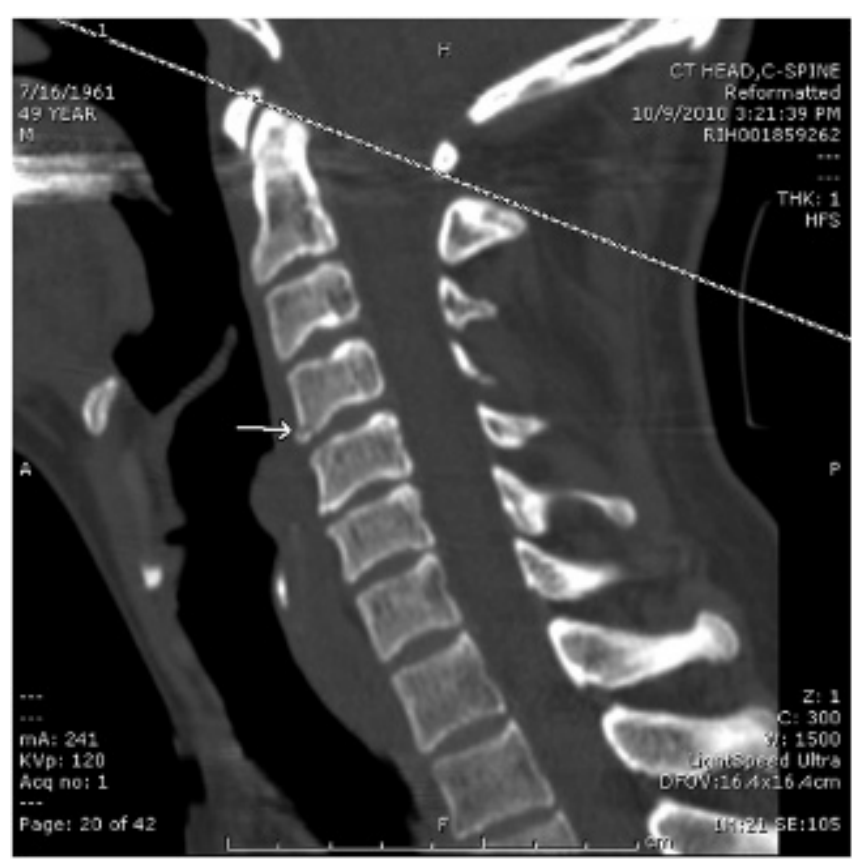

Figure 2. C4 anterior vertebral body, extension teardrop fracture.

ultrasound courses could set the example. Further research could examine whether the utility of CT training courses for emergency physicians can increase their sensitivity sufficiently to safely clear cervical spines on CT prior to a radiologist's review. Further work could focus on the specific subset of low- to moderate-risk trauma patients who are awake and alert and allow for a clinical assessment by the emergency physician. Such a prospective study could examine the combined sensitivity of the clinical examination and emergency physician CT interpretation.

\section{CONCLUSION}

Although emergency physicians successfully identified a large proportion of cervical spine injuries on CT, they were not sufficiently sensitive to accurately exclude clinically important injuries. Emergency physicians should rely on a radiologist's review of a cervical CT scan prior to discontinuing cervical spine precautions.

Competing interests: None declared.

\section{REFERENCES}

1. Greenbaum J, Walters N, Levy PD. An evidence-based approach to radiographic assessment of cervical spine injuries in the emergency department. 7 Emerg Med 2009; 36:64-71, doi:10.1016/j.jemermed.2008.01.014.

2. Grossman MD, Reilly PM, Reilly PM, et al. National survey of the incidence of cervical spine clearance in the U.S. trauma centres. 7 Trauma 1999;47:684, doi:10.1097/ 00005373-199910000-00012.

3. Steill IG, Wells GA, Vandemheen KL, et al. The Canadian C-Spine Rule for Radiography in Alert and Stable Trauma Patients. FAMA 2001;286:1841-8, doi:10.1001/jama.286. 15.1841.

4. Hoffman JR, Mower WR, Wolfson AB, et al. Validity of a set of clinical criteria to rule out injury to the cervical spine in patients with blunt trauma. National Emergency X-Radiography Utilization Study Group. $N$ Engl $\mathcal{F}$ Med 2000;343:94-9, doi:10.1056/NEJM200007133430203.

5. Daffner RH. Controversies in cervical spine imaging in trauma patients. Emerg Radiol 2004;11:2-8, doi:10.1007/ s10140-004-0360-5.

6. Holmes JF, Akkinepalli R. Computed tomography versus plain radiography to screen for cervical spine injury: a meta analysis. F Trauma 2005;58:902-5, doi:10.1097/01. TA.0000162138.36519.2A.

7. Kortbeek JB, Al Turki SA, Ali J, et al. Advanced Trauma Life Support 8th edition: the evidence for change. 7 Trauma 2008;64:1638-50, doi:10.1097/TA.0b013e3181744b03.

8. Como JJ, Diaz JJ, Dunham CM, et al. Practice management guidelines of the identification of cervical spine injuries following trauma: update for the Eastern Association of the Surgery of Trauma Practice Management Guidelines Committee. 7 Trauma 2009;67:651-9, doi:10.1097/TA. 0b013e3181ae583b.

9. Thomas J, Rideau AM, Paulson EK, et al. Emergency department imaging: current practice. 7 Am Coll Radiol 2008; 5:811-6, doi:10.1016/j.jacr.2008.02.027.

10. Stelfox HT, Velmahos GC, Gettings E, et al. Computed tomography for early and safe discontinuation of the cervical spine immobilization in the obtunded multiply injured patients. 7 Trauma 2007;63:630-6, doi:10.1097/TA. 0b013e318076b537.

11. Harding J, Craig M, Jakeman N, et al. Emergency physician interpretation of head CT in trauma and suspected subarachnoid haemorrhage - is it viable? An audit of current practice. Emerg Med 7 2010;27:116-20, doi:10.1136/emj. $\underline{2008.071688}$.

12. Stengel D, Ottersbach C, Matthes G, et al. Accuracy of single-pass whole-body computed tomography for detection of injuries in patients with major blunt trauma. CMAJ 2012; 184:869-75, doi:10.1503/cmaj.111420. 